\title{
Magnetic Resonance Arthrography, a valuable pre-operative imaging modality in femoro-acetabular impingement
}

\author{
Nevien Ezzat El-Liethy ${ }^{1 *} \mathbb{D}$, Rania Zeitoun ${ }^{1} \mathbb{D}$, Heba Ahmed Kamal ${ }^{1} \mathbb{D}$ and Ahmed Hazem Abd El-Azeem²
}

\begin{abstract}
Background: The diagnostic accuracy of MR arthrography in preoperative assessment of labral tears and chondral abnormalities in femoroacetabular impingement patients.

A non-randomized control study including 31 FAl patients (17 male and 14 females, mean age 31.9 years). All patients underwent MR arthrography after US-guided intra-articular contrast injection. Conventional and MR arthrography images were evaluated for bone abnormalities (including alpha angle and acetabular depth measurements), labral tears, and chondral abnormalities. The results were correlated to arthroscopy as the gold standard. Sensitivity, specificity, PPV, and NPV in the detection of labral tears and chondral abnormalities were statistically calculated.

Results: The included FAl patients presented cam (mean age 30.4 years \pm 6.8 years), pincer (mean age 33.6 years \pm 9.8 years), and mixed (mean age 36.6 years \pm 12.9 years) types with the predominance of cam type. Cam type predominated in the male, while pincer and mixed types predominated in female patients. MR arthrography detected 41 labral tears in 23 patients with 87.5\%, 71.4\%, 91.3\%, and 62.5\% sensitivity, specificity, PPV, and NPV, respectively, and detected chondral abnormalities in 13 patients with 66.7\%, 92.3\%, 92.3\%, and $66.7 \%$ sensitivity, specificity, PPV, and NPV, respectively.

Conclusion: MR arthrography is a valuable imaging modality in preoperative assessment of FAl patients. Besides identifying the type of impingement through alpha angle and acetabular depth measurements, it detects labral tears with high sensitivity and PPV. Although less sensitive in detection of chondral abnormalities, our results showed high specificity.
\end{abstract}

\section{Background}

Femoroacetabular impingement (FAI) is defined as abnormal femoral acetabular contact, within the normal range of motion, and attributed to changes of the anatomical configuration of the acetabulum and/ or the femoral head-neck. It was initially described by Myers et al. [1] and was reintroduced by Ganz et al. [2] with the recognition that non-united femoral neck fractures healed in retroversion could

\footnotetext{
*Correspondence: nevienelliethy@yahoo.com

'Department of Diagnostic and Interventional Radiology, Kasr Al-Ainy Faculty of Medicine, Cairo University, Giza, Egypt

Full list of author information is available at the end of the article
}

cause abnormal contact between the femoral neck and acetabular rim and lead to sped up posttraumatic osteoarthritis. Over the past two decades, Ganz et al. [2] postulated that unrecognized developmental alterations and mal-orientations of the hip may be the underlying cause of primary or idiopathic hip osteoarthritis [1-4]. Femoroacetabular impingement is considered one of the causes of chronic hip pain, and it matters in the development of osteoarthritis. Patients present with groin pain with hip rotation, in the sitting position, or during or after sports activities [5, 6]. It is divided into two types: cam and pincer, and a mixed pattern is often present, with one of the two types predominating. In cam type, an abnormal contour of the femoral head-neck junction is described, resulting in impingement against the 
acetabulum, particularly with flexion and/or internal rotation of the hip. It is more common in young men at an average age of 32 years. Pincer impingement is caused by an acetabular abnormality, usually anterior, resulting in over-coverage of the femoral head. It is more common in middle-aged women at an average age of 40 years [5, 7-9].

Femoroacetabular impingement is a clinical diagnosis based upon clinical history and physical examination. Imaging is used to support the diagnosis by detection of the spectrum of findings that may represent a predisposing etiological factor (e.g., acetabular retroversion, decreased femoral head-neck offset, developmental dysplasia of the hip, Perthe's disease, slipped capital femoral epiphysis, malunited fractures) or a consequent pathology (e.g., premature degenerative osteoarthritis, labrum tear and cartilage degeneration) [10]. While conventional radiography and computed tomography (CT) provide adequate information regarding bone abnormalities, magnetic resonance imaging (MRI) provides additional value in showing labrum and cartilage abnormalities [1012]. Magnetic resonance (MR) arthrography is now considered the best imaging modality for evaluation of the internal hip pathology allowing better visualization of the joint internal structures by the help of better distention and higher contrast resolution obtained by intra-articular gadolinium [13].

It is important to know that surgery is a good option for FAI patients in the absence of advanced degenerative changes and without extensive articular cartilage damage. So, preoperative imaging is dedicated to describe the type of impingement and underlying etiology, to detect labral tears and cartilage degeneration, and to rule out other hip abnormalities. All are factors that influence the surgical plan [14].

The purpose of this study is to evaluate the diagnostic value of MR arthrography in preoperative assessment of labral tears and chondral abnormalities in femoroacetabular impingement patients, with reference to hip arthroscopy results as the gold standard.

\section{Methods}

\section{Patients}

We designed a non-randomized control study for patients clinically suspected to have FAI. We met 50 patients presenting by chronic hip or groin pain and/or clinically suspected to have FAI, referred to the Radiology department, during the time span: March 2015 to July 2016. The study included 31 (chosen according to the age group) FAI patients (17 male and 14 female), age range 17-52 years, and mean age 31.9 years. The included patients underwent conventional MRI and MR arthrography to identify labral and chondral abnormalities, and the results were correlated to arthroscopy as the gold standard. We excluded patients whose clinical data or conventional MR imaging revealed bone or joint diseases other than FAI (e.g., avascular necrosis, fractures, and bone tumor) or not confirmed as FAI by conventional MR measurements, and patients who missed arthroscopy.

\section{Magnetic resonance imaging}

The patients were examined using MRI machine: GYROSCAN INTERA 1.5T MAGNET (PHILPS). The patients lay supine with the leg in slight internal rotation. For all the patients, conventional MRI sequences were obtained (Table 1). Images were reviewed to exclude other pathologies; US-guided intra-articular contrast injection was done.

\section{Technique of ultrasound (US)-guided intra-articular contrast injection (Fig. 1)}

- The device used is Sonoline Si-250 Elega Imaging System Siemens (Germany) ultrasound device that is equipped by $18-\mathrm{MHz}$ linear array transducer for the musculoskeletal part probe.

- The area is prepared and draped in a sterile fashion, then the subcutaneous tissue is locally anesthetized.

- The needle tip 22 gauge is advanced in an anterior, posterior direction until it reaches the femoral head neck junction then injection of contrast mixture starts (the mixture used is composed of $1 \mathrm{mmol}$ gadopentatedimeglumine, $5 \mathrm{ml}$ iodinated contrast, $3 \mathrm{ml}$ Xylocaine, and completed to $20 \mathrm{ml}$ with sterile saline).

Magnetic resonance arthrography After intra-articular contrast injection, the patient was sent to MRI scanner in a period not exceeding $30 \mathrm{~min}$. The postcontrast scan included different imaging sequences and planes (Table 1).

\section{Images interpretation and analysis}

The produced MR conventional and post intraarticular contrast injection images were transferred to a workstation. For each examined joint, the following were assessed and reported.

Bone changes Alpha angle is measured in the axial oblique plane by (Fig. 2) placing a circle around the oblique axial circumference of the femoral head, drawing a line passing through the narrowest portion 
Table 1 Protocol of MRI

\begin{tabular}{|c|c|c|c|c|c|c|}
\hline & FOV & Slice thickness & Matrix & TR & TE & NSA \\
\hline \multicolumn{7}{|l|}{ Conventional MRI } \\
\hline Axial T1 TSE & $14 \mathrm{~cm}$ & $4 \mathrm{~mm}$ & $201 \times 512$ & $500 \mathrm{~ms}$ & $10-15 \mathrm{~ms}$ & 3 \\
\hline Axial T2 TSE & $14 \mathrm{~cm}$ & $4 \mathrm{~mm}$ & $201 \times 512$ & $4000-5000 \mathrm{~ms}$ & $110-120 \mathrm{~ms}$ & 3 \\
\hline Axial STIR & $14 \mathrm{~cm}$ & $4 \mathrm{~mm}$ & $201 \times 512$ & $4000-5000 \mathrm{~ms}$ & $110-120 \mathrm{~ms}$ & 3 \\
\hline Coronal STIR & $14 \mathrm{~cm}$ & $4 \mathrm{~mm}$ & $512 \times 256$ & $4000-5000 \mathrm{~ms}$ & $110-120 \mathrm{~ms}$ & 4 \\
\hline Sagittal T2 & $14 \mathrm{~cm}$ & $4 \mathrm{~mm}$ & $512 \times 256$ & $4000-5000 \mathrm{~ms}$ & $110-120 \mathrm{~ms}$ & 3 \\
\hline \multicolumn{7}{|l|}{ MR arthrography } \\
\hline Coronal T1 FAT SAT post-contrast & $15 \mathrm{~cm}$ & $4 \mathrm{~mm}$ & $512 \times 256$ & $450-650 \mathrm{~ms}$ & $10-16 \mathrm{~ms}$ & 3 \\
\hline Axial oblique T1 FAT SAT post-contrast & $15 \mathrm{~cm}$ & $4 \mathrm{~mm}$ & $512 \times 256$ & $450-650 \mathrm{~ms}$ & $10-16 \mathrm{~ms}$ & 3 \\
\hline Sagittal T1 FAT SAT post-contrast & $15 \mathrm{~cm}$ & $4 \mathrm{~mm}$ & $512 \times 256$ & $450-650 \mathrm{~ms}$ & $10-16 \mathrm{~ms}$ & 3 \\
\hline
\end{tabular}

TSE turbo-spin echo, STIR short T1 inversion recovery, FAT SAT fat saturation, FOV field of view, TR repetition time, TE echo time, NSA number of signal averages

of the femur neck to the center of the femur head, and then placing a second line that extends from the point of intersection of the first line and the center of the femoral head to a point where the osseous anterior femoral head intersects the circle. Alpha angle is abnormal if the measured value is $>55^{\circ}$, showing cam type.

Acetabular depth (Fig. 3) is measured in the axial oblique plane by placing a line connecting the anterior and posterior acetabular rim then another line passing through the center of the femoral head and running parallel to the first line.

The value is classified as "positive" if the center of the femoral head is lateral to the line that connects the anterior and the posterior acetabular rim, and value is negative if the center of the femoral head is medial to the line which indicates deep acetabulum, a sign of pincer type.
Bone marrow edema, subchondral erosions and cysts, bone bumps at the head/neck junction, and bone spurs at the acetabulum margins were evaluated from conventional MR images

Labrum abnormalities A labral tear was diagnosed by a high signal contrast medium entered through the inner of surface of acetabular labrum or located between the acetabular labrum and acetabular edge or presence of an associated labral cyst. Confirmation was done by the presence of any of these findings in other imaging planes. Labral tears were classified by their sites into antero-superior, antero-inferior, postero-superior, and postero-inferior. Anterior and posterior tears were detected using axial, sagittal, and radial planes while superior and inferior tears were detected on coronal and radial planes.
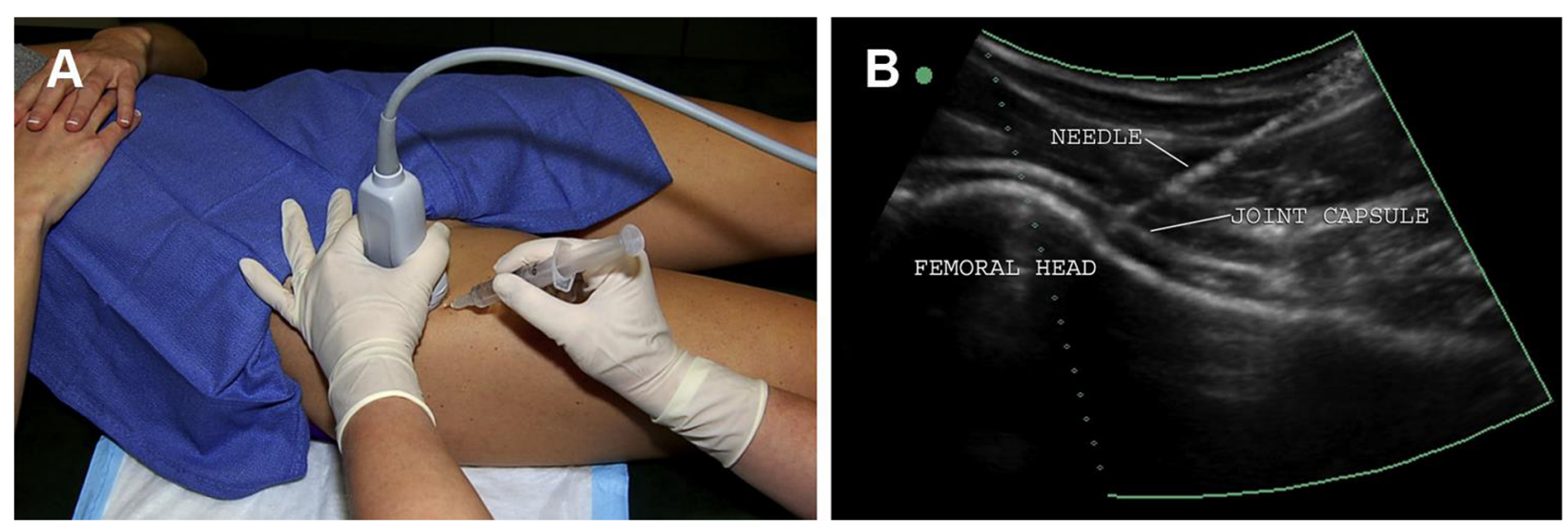

Fig. 1 a The needle is inserted in plane with the transducer, which allows visualization of the needle throughout the course of its advancement to the capsule. $\mathbf{b}$ The needle can be seen entering the right hip joint capsule at the femoral head-neck junction 


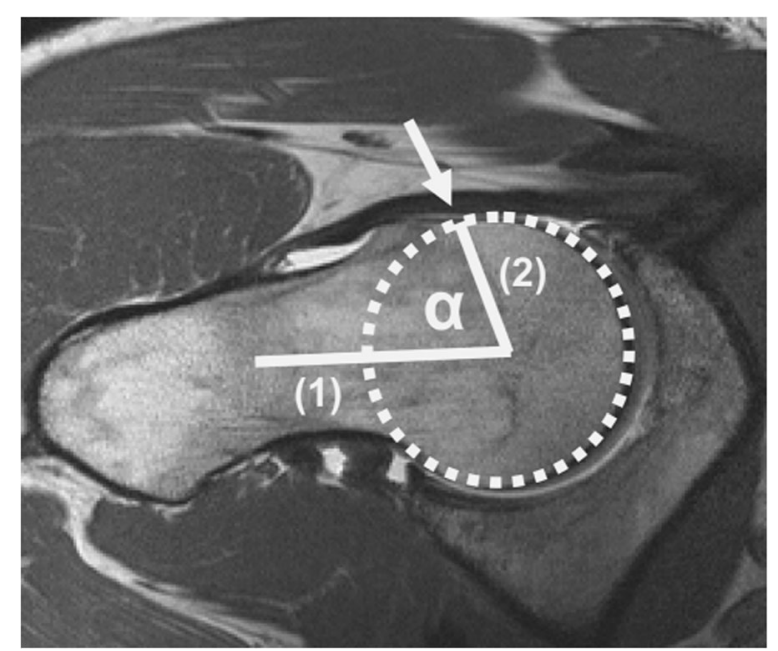

Fig. 2 Measurement of the alpha angle is shown. A best-fit circle is drawn over the femoral head. The alpha angle is formed by the axis of the femoral neck (1) and a line (2) drawn from the femoral head center to the point where the head extends beyond the margin of the best fit circle (arrow)

Chondral abnormalities Defects were identified by noting fluid signal replacing the normal intermediate signal intensity of the cartilage.

Other findings These include herniation pits, paralabral cyst formation, synovial effusion, and bursa.

\section{Arthroscopy}

All the included patients had done arthroscopy, and the results were used as a gold standard.

\section{Statistical analysis}

Data was analyzed using SPSS win statistical package version 21 (SPSS Inc., Chicago, IL). Numerical data were expressed as mean, and standard deviation or median and range as appropriate. Qualitative data were expressed as frequency and percentage. Chisquare test (Fisher's exact test) was used to examine the relation between qualitative variables. For quantitative data, a comparison between two groups was done using either student $t$ test or Mann-Whitney test (non-parametric $t$ test) as appropriate. A $P$ value of less than 0.05 was considered significant. The sensitivity, specificity, positive predictive value (PPV), and negative predictive value (NPV) of MR arthrography for diagnosing the acetabular labral tears and chondral abnormalities were calculated, using the results of hip arthroscopy as the gold standard.

\section{Results}

The included 31 patients had FAI based upon the alpha angle and acetabular depth measurements using axial oblique MR images. They were classified into the cam (Figs. 1 and 3), pincer, and mixed types (Figs. 2 and 4) (Table 2).

The measured alpha angle exceeded the normal value $\left(<55^{\circ}\right.$; with mean $\left.76^{\circ} \pm 7.8\right)$ in 28 patients $(22$ cam and 6 mixed types) and was found $>55^{\circ}$, with mean $52^{\circ} \pm 1.1$ in 3 patients of pincer type. The acetabular depth measurement was positive in 22 patients of cam type and negative in 9 patients (3 pincer type and 6 mixed type).
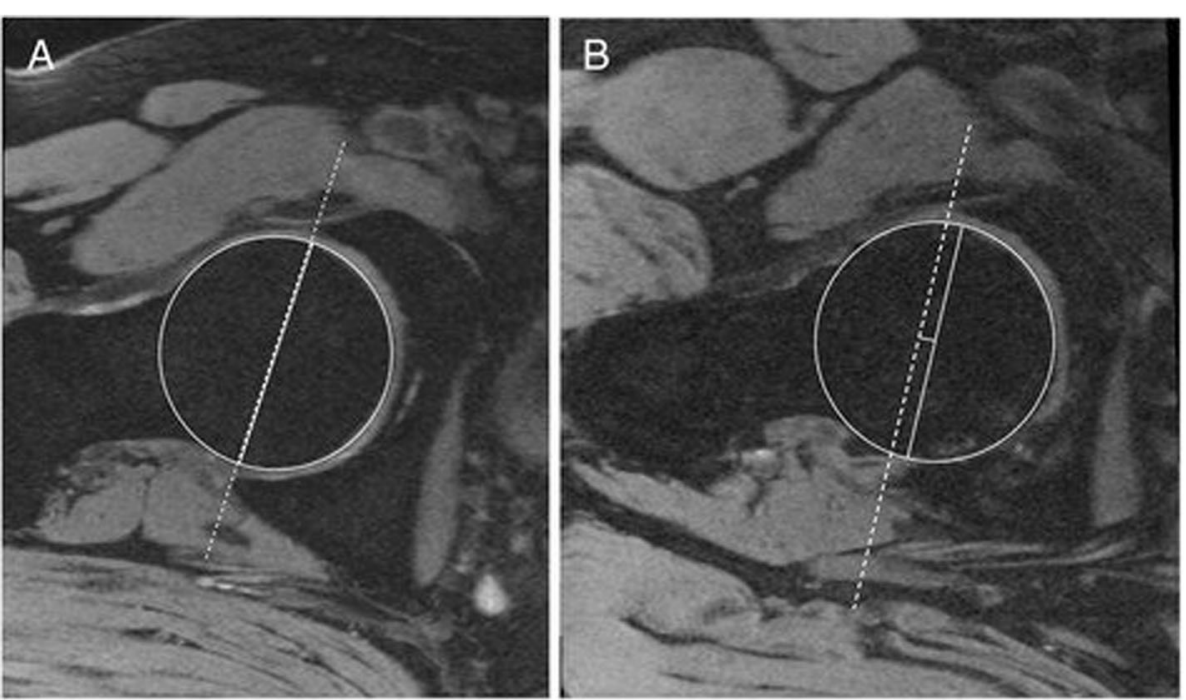

Fig. 3 a A line joining anterior and posterior bony rim-do not include labrum. This is the rim line (dotted). Then, $\mathbf{b}$ draw another line parallel to the above that passes through the center of the head. This is the center line. Normally rim line should be lateral to center line (measure in $\mathrm{mm}$ with $\mathrm{a}+\mathrm{sign}$ ) 

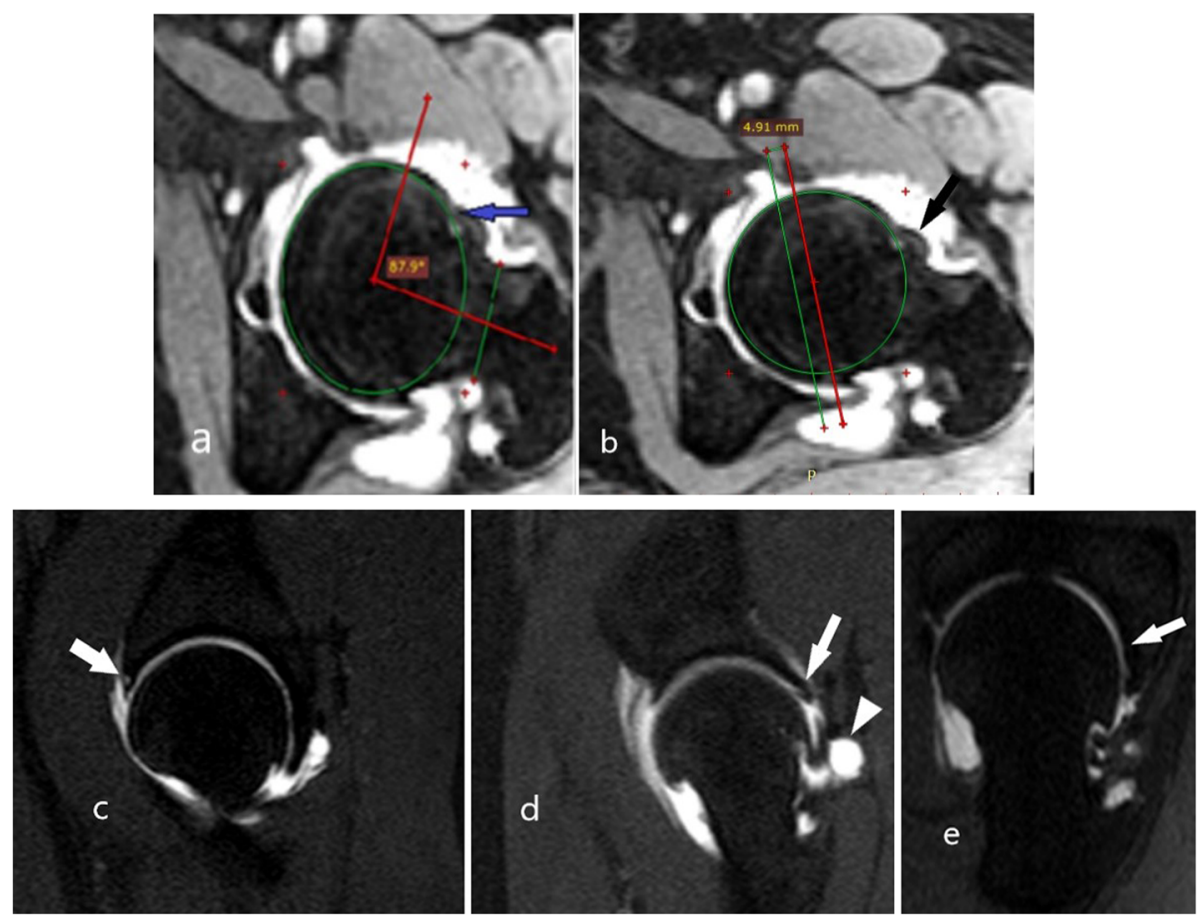

Fig. 4 Femoroacetabular impingement (cam type) in a 25-year-old male patient, complaining of left hip pain and limitation of movement. a, b Axial oblique T1 fat sat post-contrast: a increased alpha angle $\left(87.9^{\circ}\right)$ and abnormal bone bump at the head-neck junction (arrow), b normal acetabular depth $(+4.9 \mathrm{~mm})$. c-e Sagittal $\mathrm{T} 1$ fat sat post-contrast: $\mathbf{c}$ anterior labral tear detected as high signal contrast within the labrum substance (arrow), d posterior labral tear detected as high signal contrast, passing within the edge of the labrum (arrow) associated with filling of paralabral cyst (arrow head), e irregular degenerated cartilage (arrow)

In cam type, a male predominance is noticed, representing about $72 \%$ of the cam cases. Pincer and mixed types were more common in females in our study, with the female gender representing $100 \%$ of the pincer cases and $83 \%$ of the mixed type. The relationship between sex and type of impingement was proved statistically significant with a $P$ value $=0.005$. The difference in the ages of patients among different FAI was significant $(P$ value $=0.033)$. Cam type (range, $17-40$ years [mean, 30.4 years \pm 6.8 years], pincer type (range, 27-45 years [mean, 33.6 years \pm 9.8 years], and mixed type (range, 21-52 years [mean, 36.6 years \pm 12.9 years].

The bone changes included subchondral marrow edema and pseudo-cysts in 10 patients (32.3\%), visually detectable osseous bumps at the head/neck junction in 20 patients (64.5\%), and loss of head and neck waist in 8 patients (25.8\%) (Figs. 1 and 2). On MR arthrography images, 41 labral tears were identified in 23 FAI patients ( $74.2 \%$ of studied patients). According to their sites, the tears were classified into four quadrants: antero-superior, postero-superior, antero-inferior, and postero-inferior (Table 3). On the other hand, 42 labral tears were identified on arthroscopy in 24 FAI patients $(77.4 \%$ of studied patients) (Table 3). MR arthrography missed labral tears (Figs. 4, 5, 6, and 7) in three patients (three false negative tears, two at the antero-superior quadrant and one at the postero-superior quadrant), while two tears in other two patients were found to

Table 2 Types of FAl in the study according to alpha angle and acetabular depth measurements

\begin{tabular}{llll}
\hline Measurements & Type of FAl & Number of patients & Percentage \\
\hline Alpha angle $>55$ and acetabular depth is negative & Cam type & 22 & $71 \%$ \\
Alpha angle $<55$ and acetabular depth is positive & Pincer type & 3 & $9.7 \%$ \\
Alpha angle $>55$ and positive acetabular depth & Mixed & 6 & $19.3 \%$ \\
Total & & 31 & \\
\hline
\end{tabular}


Table 3 The number of labral tears at different quadrants and the number of patients having chondral abnormalities as detected by MR arthrography and arthroscopy in FAl patients

\begin{tabular}{lll}
\hline & MR arthrography & Arthroscope \\
\hline Labral tears & & \\
Antero-superior & $30(73.2 \%)$ & $30(71.4 \%)$ \\
Postero-superior & $5(12.2 \%)$ & $6(14.2 \%)$ \\
Antero-inferior & $4(9.7 \%)$ & $4(9.5 \%)$ \\
Postero-inferior & $2(4.9 \%)$ & $2(4.7 \%)$ \\
Total number of labral tears & 41 & 42 \\
Total number of patients & 23 & 24 \\
having labral tears & & \\
Cartilage abnormalities & & 18 \\
Number of patients & 13 & \\
\hline
\end{tabular}

be sublabral sulcus on arthrography (two false positive tears at the antero-superior quadrant). The diagnostic performance parameters of MR arthrography in the detection of labral tears in FAI patients, according to the statistics are listed in Tables 4 and 5. Magnetic resonance arthrography detected articular chondral abnormalities in 13 patients (42\%) and missed chondral abnormalities in five patients. (Tables 3 and 4 ) Other findings noted on the MR arthrography included labral cysts (four patients, 12.9\%) and synovial pit (three patients, 9.7\%).

\section{Discussion}

Femoroacetabular impingement is an important cause of chronic hip pain and a factor in developing osteoarthritis. It is classified into the cam, pincer, or mixed types according to the underlying morphological bone abnormalities. In cam type, a spherical configuration of the femur head and loss of the normal head, neck waist is described, while in pincer type, focal or general acetabular over coverage is described $[5,6,8,9,15]$.

Among the included patients in our study, cam type predominated followed by mixed then pincer types. The high incidence of cam type has been stated by other studies [16, 17], yet some studies pointed to prevalence of mixed types [13].
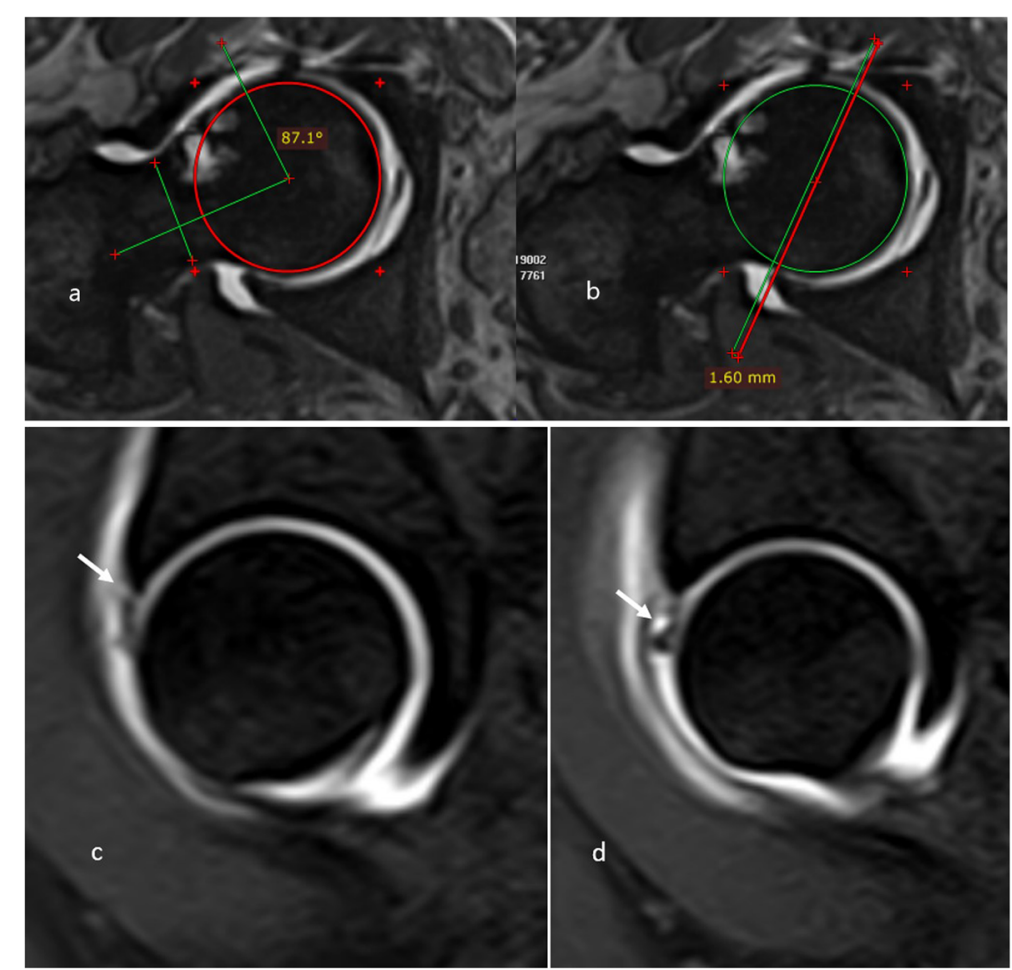

Fig. 5 Femoroacetabular impingement (mixed type) in a 40-year-old female, complaining of right hip pain and limitation of movement. a, b Axial oblique $\mathrm{T} 1$ fat sat post-contrast: a increased alpha angle $\left(87.1^{\circ}\right)$, with the loss of the normal head-neck waist being slightly convex and showing multiple cysts, $\mathbf{b}$ deep acetabulum $(-1.6 \mathrm{~mm})$. c, $\mathbf{d}$ Sagittal T1 fat sat post-contrast: $\mathbf{c}$ anterior labral complete tear detected as high signal contrast extending across the labrum edge to base and disrupting its acetabular attachment (arrow in c) and associated tiny paralabral cyst (arrow in d) 

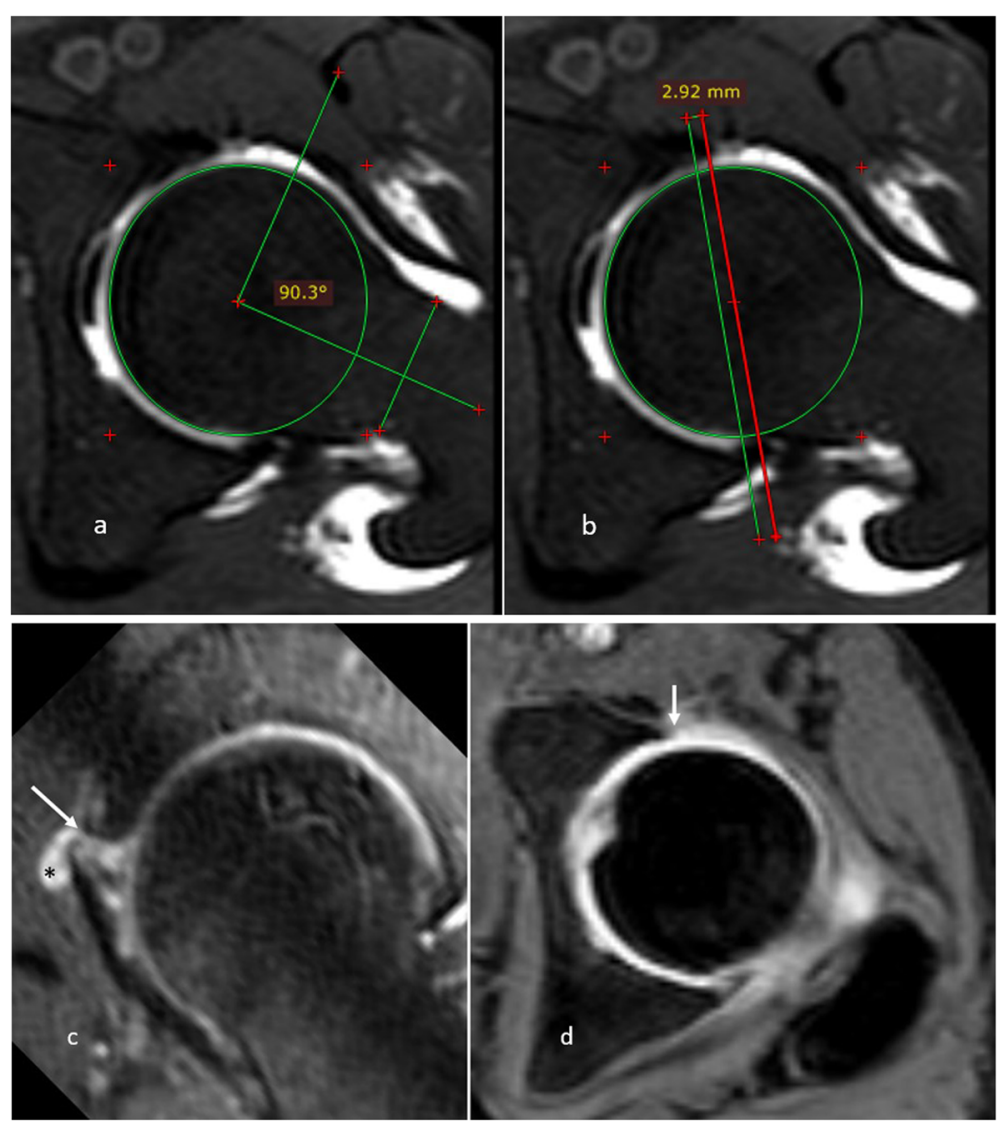

Fig. 6 Femoroacetabular impingement (cam type) in a 39-year-old male, complaining of left hip pain and limitation of movement. a, b Axial oblique T1 fat sat post-contrast: a increased alpha angle $\left(90.3^{\circ}\right)$, b normal acetabular depth (+ $\left.2.9 \mathrm{~mm}\right)$. c, d Sagittal and axial T1 fat sat post-contrast: $\mathbf{c}$ anterior labral complete tear with detachment of its acetabular attachment (arrow in c) and appear defective on axial images (arrow in $\mathbf{d}$ ) together with paralabral cyst (asterisk in $\mathbf{c}$ )

Various studies showed the superiority of MR arthrography over conventional MR imaging in the detection of labral tears, especially considering small tears, distinguishing labrum degeneration from the tear and detection of labrum detachment from the acetabulum rim [18]. Our results revealed the sensitivity, specificity, PPV, and NPV of MR arthrography in the detection of labral tears to be $87.5 \%, 71.4 \%, 91.3 \%$, and $62.5 \%$, respectively. These figures fall in and close to the ranges of calculating diagnostic accuracy parameters by other studies, where sensitivities ranged from 85 to $90 \%[8,18$, 19].

In particular, specificity ranges varied among different studies and even among two readers in the same study [20]. Tian and his colleagues [21], in their study, showed a notable higher sensitivity and specificity values, which can be explained by their use of 3-Tesla MRI allowing better accuracy.
Regarding the location of the labral tears, most of them were at the anterior-superior quadrant followed by the postero-superior quadrant, in agreement with other study reports $[19,20,22]$. The two false positive patients were shown to be sublabral sulcus at the antero-superior quadrant on arthroscopy. Sublabral sulcus is an anatomical variant that may be present at any quadrant and mimics a tear on MR arthrography. Differentiation is difficult; however, in case of sulcus variant, contrast should not extend into the labrum substance or involve the entire thickness of its base [23, 24].

Magnetic resonance arthrography had a relatively limited sensitivity $(66.7 \%)$ in detection of chondral abnormalities. The calculated sensitivities in studies by Sutter et al. [20], Mc Carthy et al. [25], and Keeney et al. [26] are $71 \%, 65 \%$, and $47 \%$, respectively. However, a relatively higher specificity is noticed, $92.3 \%$ in our study, slightly higher than Mc Carthy et al. and 

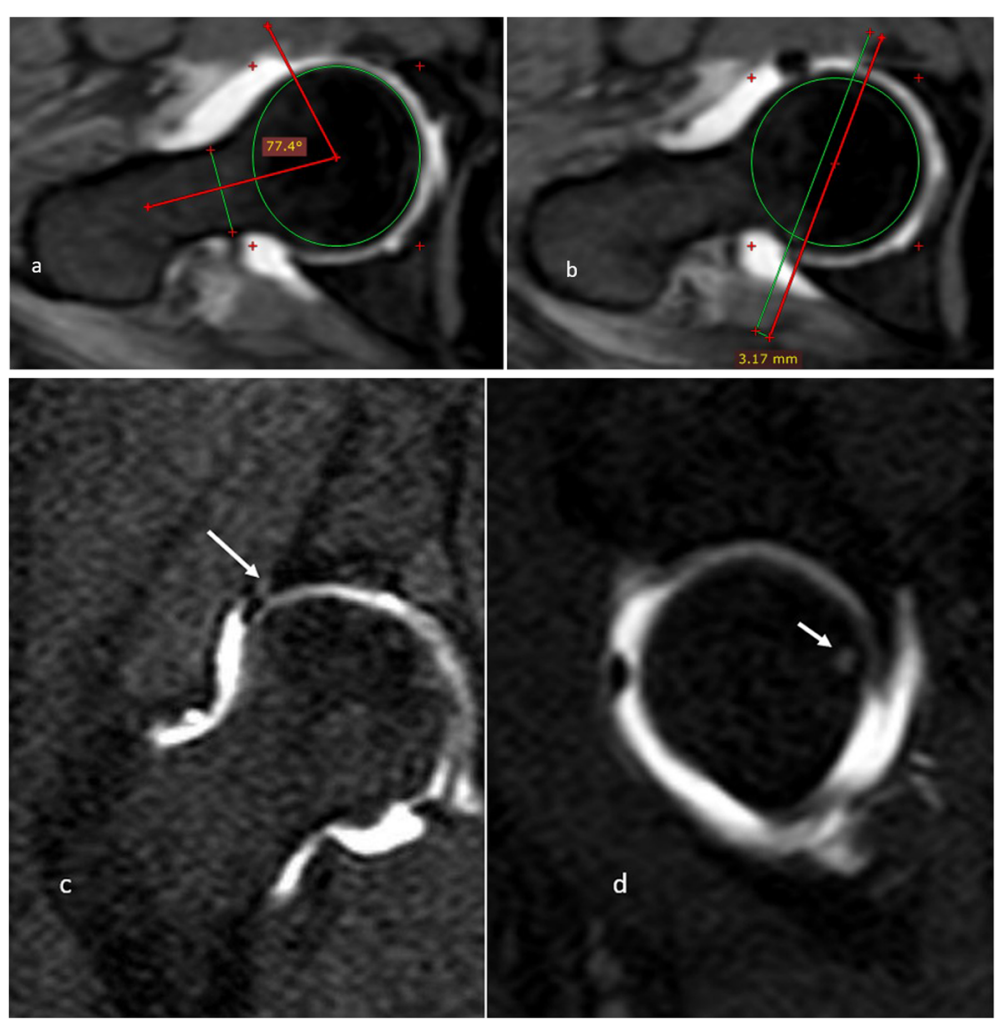

Fig. 7 Femoroacetabular impingement (mixed type) in a 48-year-old female patient, complaining of right hip pain. a, b Axial oblique $\mathrm{T} 1$ fat sat post-contrast: a increased alpha angle $\left(77.4^{\circ}\right)$, b increased acetabular depth $(-3.1 \mathrm{~mm})$. c, d coronal and sagittal $\mathrm{T} 1$ fat sat post-contrast: c anterior labral tear detected as high signal contrast across the labrum base (arrow), d irregular outline and nonuniform decreased thickness of posterior cartilage associated with posterior femoral subchondral cyst (arrow)

Keeney et al. [25, 26], $90 \%$ and $89 \%$, respectively. It had been stated that MR arthrography is better at ruling in than at ruling out chondral abnormalities, and chondral lesions may be under diagnosed, especially in their early stages [25].

\section{Limitations}

This study had one limitation: we had a relatively small sample (31 subjects).

Table 4 Measures of diagnostic performance of MR arthrography (sensitivity, specificity, PPV, and NPV) for detection of labral tears and chondral abnormalities in FAl patients with reference to arthroscope results

\begin{tabular}{lll}
\hline & $\begin{array}{l}\text { MR arthrography } \\
\text { in labral tears }\end{array}$ & $\begin{array}{l}\text { MR arthrography in } \\
\text { cartilage abnormalities }\end{array}$ \\
\hline Sensitivity & $87.5 \%$ & $66.7 \%$ \\
Specificity & $71.4 \%$ & $92.3 \%$ \\
PPV & $91.3 \%$ & $92.3 \%$ \\
NPV & $62.5 \%$ & $66.7 \%$ \\
\hline
\end{tabular}

PPV positive predictive value, NPV negative predictive value

\section{Conclusion}

Our study revealed a predominance of cam type, with the prevalence of labral tears $(77.4 \%$ of the studied patients). Magnetic resonance arthrography showed high sensitivity and PPV in the diagnosis of labral tears in FAI patients and thus can provide reliable assurance of the indication for hip arthroscopy and detailed preoperative information to the surgeon regarding the localization of tear by quadrant which help in portal selection. It is of limited sensitivity in detection of chondral abnormalities

Table 5 The diagnostic performance parameters (sensitivity, specificity, PPV, and NPV) of MR arthrography for detection of labral tears at different quadrants in FAl patients with reference to arthroscope results

\begin{tabular}{lllll}
\hline $\begin{array}{l}\text { Labral tears at different } \\
\text { quadrants }\end{array}$ & Sensitivity & Specificity & PPV & NPV \\
\hline Antero-superior & $90.9 \%$ & $77.8 \%$ & $90.9 \%$ & $77.8 \%$ \\
Postero-superior & $80 \%$ & $100 \%$ & $100 \%$ & $96.3 \%$ \\
Antero-inferior & $100 \%$ & $100 \%$ & $100 \%$ & $100 \%$ \\
Postero-inferior & $100 \%$ & $100 \%$ & $100 \%$ & $100 \%$ \\
\hline
\end{tabular}




\section{Abbreviations}

CT: Computed tomography; FAl: Femoroacetabular Impingement; MR: Magnetic Resonance; MRI: Magnetic Resonance Imaging; NPV: Negative Predictive Value; PPV: Positive Predictive Value

\section{Acknowledgements}

The authors gratefully acknowledge the valuable contributions of Dr. Lamis Elgendy, resident of radiology, and Prof. Manar Hussien, professor of radiology, to facilitate in performing this work. The authors really appreciate the role of the Kasr Al-Ainy institute and hospital for providing the student with the required type of patients and the help of reaching optimum diagnose for the proper management service.

\section{Authors' contributions}

NE gave idea and collected the patients' data and analyzed them. HK and $\mathrm{AH}$ put the study design and followed the patients postoperatively. NE and RZ wrote the paper with revision. They all approved the final version of the manuscript. The study is not sent for any other journals for publications.

\section{Funding}

This study had no funding from any resource.

\section{Availability of data and materials}

The datasets used and/or analyzed during the current study are available from the corresponding author on reasonable request.

\section{Ethics approval and consent to participate}

This study was approved by the Research Ethics Committee of the Faculty of Medicine at Cairo University in Egypt on 201572016; in compliance with Helsinki Declaration (DoH-oct20081).

All patients included in this study gave written informed consent to participate in this research. If the patient was less than 16 years old or unconscious at the time of the study, written informed consent for their participation was given by their parent or legal guardian.

\section{Consent for publication}

All patients included in this research gave written informed consent to publish the data contained within this study. If the patient was less than 16 years old, deceased, or unconscious when consent for publication was requested, written informed consent for the publication of this data was given by their parent or legal guardian.

\section{Competing interests}

The authors declare that they have no competing interests.

\section{Author details}

${ }^{1}$ Department of Diagnostic and Interventional Radiology, Kasr Al-Ainy Faculty of Medicine, Cairo University, Giza, Egypt. ²Department of Orthopaedics, Kasr Al-Ainy Faculty of Medicine, Cairo University, Giza, Egypt.

\section{Received: 21 June 2019 Accepted: 16 September 2019}

\section{Published online: 12 December 2019}

\section{References}

1. Myers SR, Eijer H, Ganz R (1999) Anterior femoroacetabular impingement after periacetabular osteotomy. Clin Orthop:93-99

2. Siebenrock KA, Schoeniger R, Ganz R (2003) Anterior femoro-acetabular impingement due to acetabular retroversion. Treatment with periacetabular osteotomy. J Bone Joint Surg Am 85-A:278-286

3. Macfarlane RJ, Haddad FS (2010) The diagnosis and management of femoral-acetabular impingement. Ann R Coll Surg Engl 92:363-367 https:// doi.org/10.1308/003588410X12699663903791

4. Amanatullah DF, Antkowiak T, Pillay K et al (2015) Femoroacetabular impingement: current concepts in diagnosis and treatment. Orthopedics 38: 185-199 https://doi.org/10.3928/01477447-20150305-07

5. Tanzer M, Noiseux N (2004) Osseous abnormalities and early osteoarthritis: the role of hip impingement. Clin Orthop:170-177;(429)

6. Ito K, Leunig M, Ganz R (2004) Histopathologic features of the acetabular labrum in femoroacetabular impingement. Clin Orthop:262-271;(429):262-71
7. Tannast M, Siebenrock KA, Anderson SE (2007) Femoroacetabular impingement: radiographic diagnosis - what the radiologist should know. Am J Roentgenol 188:1540-1552 https://doi.org/10.2214/AJR.06.0921

8. Naraghi A, White LM (2015) MRI of labral and chondral lesions of the hip. Am J Roentgenol 205:479-490 https://doi.org/10.2214/AJR.14.12581

9. Reichenbach S, Leunig M, Werlen S et al (2011) Association between camtype deformities and magnetic resonance imaging-detected structural hip damage: a cross-sectional study in young men. Arthritis Rheum 63:40234030 https://doi.org/10.1002/art.30589

10. Beall DP, Sweet CF, Martin HD et al (2005) Imaging findings of femoroacetabular impingement syndrome. Skelet Radiol 34:691-701 https:// doi.org/10.1007/s00256-005-0932-9

11. Meyer DC, Beck M, Ellis T et al (2006) Comparison of six radiographic projections to assess femoral head/neck. Asphericity: Clin Orthop PAP https://doi.org/10.1097/01.blo.0000201168.72388.24

12. James SLJ, Ali K, Malara F et al (2006) MRI findings of femoroacetabular impingement. Am J Roentgenol 187:1412-1419 https://doi.org/10.2214/AJR. 05.1415

13. Banerjee P, Mclean CR (2011) Femoroacetabular impingement: a review of diagnosis and management. Curr Rev Musculoskelet Med 4:23-32 https:// doi.org/10.1007/s12178-011-9073-z

14. Anderson LA, Peters CL, Park BB et al (2009) Acetabular cartilage delamination in femoroacetabular impingement: risk factors and magnetic resonance imaging diagnosis. J Bone Jt Surg Am 91:305-313 https://doi. org/10.2106/JBJS.G.01198

15. Pun S, Kumar D, Lane NE (2015) Review: femoroacetabular impingement: the syndrome of femoroacetabular impingement. Arthritis Rheumatol 67: 17-27 https://doi.org/10.1002/art.38887

16. Tresch F, Dietrich TJ, Pfirrmann CWA, Sutter R (2017) Hip MRI: prevalence of articular cartilage defects and labral tears in asymptomatic volunteers. A comparison with a matched population of patients with femoroacetabular impingement: hip defects in asymptomatic volunteers. J Magn Reson Imaging 46:440-451 https://doi.org/10.1002/jmri.25565

17. Pfirrmann CWA, Mengiardi B, Dora C et al (2006) Cam and pincer femoroacetabular impingement: characteristic MR arthrographic findings in 50 patients. Radiology 240:778-785 https://doi.org/10.1148/radiol.2403050767

18. Smith TO, Hilton G, Toms AP et al (2011) The diagnostic accuracy of acetabular labral tears using magnetic resonance imaging and magnetic resonance arthrography: a meta-analysis. Eur Radiol 21:863-874 https://doi. org/10.1007/s00330-010-1956-7

19. Reurink G, Jansen SP, Bisselink JM et al (2012) Reliability and validity of diagnosing acetabular labral lesions with magnetic resonance arthrography. J Bone Jt Surg Am 94:1643-1648 https://doi.org/10.2106/JBJS.K.01342

20. Sutter R, Zubler V, Hoffmann A et al (2014) Hip MRI: how useful is Intraarticular contrast material for evaluating surgically proven lesions of the labrum and articular cartilage? Am J Roentgenol 202:160-169 https://doi. org/10.2214/AJR.12.10266

21. Tian CY, Wang JQ, Zheng ZZ, Ren AH (2014) 3.0 T conventional hip MR and hip MR arthrography for the acetabular labral tears confirmed by arthroscopy. Eur J Radiol 83(10):1822-1827. https://doi.org/10.1016/j.ejrad. 2014.05.034

22. Chan Y-S, Lien L-C, Hsu H-L et al (2005) Evaluating hip labral tears using magnetic resonance arthrography: a prospective study comparing hip arthroscopy and magnetic resonance arthrography diagnosis. Arthrosc J Arthrosc Relat Surg 21: 1250.e1-1250.e8 https://doi.org/10.1016/j.arthro.2005.07.007

23. Nguyen MS, Kheyfits V, Giordano BD et al (2013) Hip anatomic variants that may mimic abnormalities at MRI: labral variants. Am J Roentgenol 201: W394-W400 https://doi.org/10.2214/AJR.12.9860

24. Studler U, Kalberer F, Leunig M et al (2008) MR arthrography of the hip: differentiation between an anterior sublabral recess as a normal variant and a labral tear. Radiology 249:947-954 https://doi.org/10.1148/radiol.2492080137

25. McCarthy JC, Glassner PJ (2013) Correlation of magnetic resonance arthrography with revision hip arthroscopy. Clin Orthop Relat Res 471:40064011 https://doi.org/10.1007/s11999-013-3202-5

26. Keeney JA, Peelle MW, Jackson J et al (2004) Magnetic resonance arthrography versus arthroscopy in the evaluation of articular hip pathology. Clin Orthop 429:163-169 https://doi.org/10.1097/01.blo.0000150125.34906.7d

\section{Publisher's Note}

Springer Nature remains neutral with regard to jurisdictional claims in published maps and institutional affiliations. 